\title{
Extrapulmonary Tuberculosis is the Leading Presentation among Hospitalized Children: A Single- Center Experience in a Decade
}

\author{
Christine W.S. Basanti ${ }^{1}$, Sonia A. EL Saiedi' ${ }^{1}$, Mai M.K. Moawad ${ }^{2}$, Azza K. \\ Abdelmegeid ${ }^{1}$ \\ 1 Department of Pediatrics, Faculty of Medicine, Cairo University, Egypt; \\ christine.w.shaker@gmail.com,myheartclinic@windowslive.com, azzakamal1718@gmail.com, \\ 2 Department of Pediatrics, Fayoum General Hospital, Egypt; maimahdy927@gmail.com \\ * Correspondence: christine.w.shaker@gmail.com \\ Received: 25/5/2021; Accepted: 17/6/2021; Published online: 25/6/2021.
}

\begin{abstract}
:
Background: With an incidence of twelve tuberculosis (TB) cases for every 100,000 persons in 2019, Egypt is considered a medium-burden country. Nevertheless, guidelines and studies for admission of pediatric TB cases are lacking in developing countries.

Aim of the Work: To describe the clinical presentations of hospitalized pediatric TB cases.

Materials and Methods: A retrospective analytical study of data collected from the inpatient medical files of children with confirmed TB, from the archives of Giza Chest Hospital (Omraneya), Egypt was implemented during January 2009 to the end of 2018.

Results: Of the 76 children hospitalized with TB, 42 were males with a male to female ratio of 1.2:1, 61 (80.3\%) patients were from rural areas, and $65(85.5 \%)$ were above six years of age. Extra-pulmonary TB was more common (45 patients; $59.2 \%$ ) than pulmonary TB (31 patients; $40.8 \%$ ). Tuberculous $\mathrm{LN}$ affection was $(\mathrm{N}=20) 26.2 \%$ of total patients, followed by pleural affection $(\mathrm{N}=17)$, then affection of bones $(\mathrm{N}=4)$. CNS involvement was among least common presentations $(\mathrm{N}=4 ; 5.3 \%)$, but was the only type of TB to occur more in preschool children. Moreover, there was an annual rate of change of -2.714 in the recorded numbers of pediatric TB inpatients with no cases in the last two years.

Conclusion: Extra-pulmonary TB was more common than pulmonary TB among the hospitalized children. Lymph nodes were the most common extra-pulmonary site of affection. School-aged children were a majority as well as rural residents. These findings warrant evoking awareness among physicians about the various presentations of pediatric TB.
\end{abstract}

Level of Evidence of Study: III (1).

Keywords: clinical presentation; Egypt; inpatient; pediatric; tuberculosis.

Abbreviations: BCG: Bacille Calmette Guerin; CNS: central nervous system; CXR: chest X ray; DOTS: directly observed treatment short-course; EPTB: Extra-pulmonary tuberculosis; LN: Lymph node: M. tuberculosis: Mycobacterium tuberculosis: MDR: multi drug resistant; N: number; NAA: nucleic acid amplification; NTP: The National Tuberculosis Control Program; PTB: pulmonary tuberculosis; TB: Tuberculosis; WHO: World Health Organization.

\section{Introduction}

Active tuberculosis (TB) continues to be the dominant cause of mortality in the world from a single infectious agent (1.2 million fatalities in 2019), and a global incidence of around 10 million human beings, around ten percent of whom are children (2).

Detecting and treating TB cases in a timely manner can significantly reduce community transmission, morbidity and mortality. Diagnosis is typically confirmed by detection of Mycobacterium tuberculosis bacilli in culture, or via nucleic acid amplification (NAA) testing (3). But since children with tuberculosis usually have paucibacillary disease and contribute little to disease transmission, their diagnosis and treatment has not been considered a priority by TB control programs until relatively recently. This underdiagnosis of childhood pulmonary 
tuberculosis (PTB) presented an obstacle to effective management. Consequently, children have been carrying a huge disease burden from tuberculosis, particularly in endemic areas (4).

The incidence rate of TB in Egypt was 12 per 100.000 people as per the World Health Organization (WHO) estimate in 2019, 6\% of which were children 14 years and younger (5). The National Tuberculosis Control Program (NTP) in Egypt implements a strategy for screening, diagnosing, notifying, and registering $\mathrm{TB}$ cases (6).

The current first-line treatment strategies for drug-susceptible tuberculosis call for the use of as much as four antimicrobial medications, for a course of 6 months. This can generally attain a cure rate of $85 \%$, and up to $98 \%$, for new drug-susceptible TB cases (2), especially when The Directly Observed Treatment Short-course (DOTS) guidelines are advocated (7).

These efforts have led to a reduction in the incidence of TB globally, both in developed countries $(8,9)$ as well as in high-burden developing ones $(10,11)$. However, the rate of decrease is still lagging behind the ambitious End TB Strategy set by WHO (12). This could be due to the continuing emergence of multi-drug-resistant TB strains (MDR). MDR-TB cases are almost irremediable by the classic first-line treatment (13).

Many efforts at modifying guidelines for hospitalization of cases of TB, have contributed to a substantial improvement in outcome $(14,15)$. The aim of this study was to assess the presentations of TB among the hospitalized children, to help understand demographics and clinical presentations that is vital for appropriate suspicion, diagnosis and treatment of TB.

\section{Material and Methods}

The study at hand is a descriptive, retrospective study conducted in Giza Chest Hospital (Omraneya), Egypt. Giza Chest Hospital is one of 35 specialized chest hospitals in Egypt included in the NTP (6), and one of 3 hospitals (along with Imbaba and Ayat Chest Hospitals) in Giza Governorate. Giza is the second largest governorate in Egypt with around 9 million inhabitants (16). All inpatient files (hand-written, paper files) of children under 18 years with a confirmed diagnosis of tuberculosis, from January, 2009 to December, 2018 were pulled out of the archives and reviewed in details (Figure 1). Extracted data were tabulated in an excel sheet where patients were designated serial numbers and kept anonymous. The Pediatric Department Committee of Research and Higher Studies Research Committee of Faculty of Medicine, Cairo University approved the study in compliance to Helsinki declaration guidelines (17).

\section{Methods}

Data collected included all the recorded symptoms (night sweats, night fever, sweating, as well as loss of weight and appetite). History of previous diseases and family history were also noted. Clinical evidence and investigation results (including positive tuberculin tests, laboratory and radiological data), as well as the diagnosis of pulmonary or extra pulmonary TB were also collected and tabulated. Yearly numbers of pediatric inpatients were tallied. Data were then coded and analyzed.

\section{Statistical Analysis}

Statistical analysis was performed using the IBM Statistical Package of Social Sciences (SPSS V -21). The data were presented as numbers and percentages.. Data were tabulated, as quantitative and qualitative data where parametric and non-parametric data analysis was employed respectively. Significance of the results was considered if the $p$ value was less than 0.05 The annual rate of change was calculated by the general trend equation " $y=m x+b$ " where $y$ is the number of children, $\mathrm{x}$ is time, $\mathrm{m}$ is the slope and $\mathrm{b}$ is the $\mathrm{y}$-intercept.

\section{Results}

Demographically, male affection comprised $55.3 \%$ of cases (1.2:1). School-aged children (six years and above) represented the major sector of children with illness at $85.5 \%$ of recorded pediatric patients. In addition, $80.3 \%$ came from rural residential areas (table 1). From the clinical standpoint, the majority of the children diagnosed with TB (93.4\%) had a scar of BCG vaccination. Interestingly, $59.2 \%$ of our pediatric cases had EPTB where lymph node (LN) 
affection represented the majority of them and CNS involvement was the least (table 2). However, CNS affection was the only TB form to occur more in preschool children (table 5).

Regarding investigations, Tuberculin test results were positive in $92.1 \%$ of cases. However, registration of the results of the other diagnostic modalities was missing in $57.9 \%$ of patients for CXRs, and 59.2\% for sputum cultures (table 2). It was not clear whether these tests were not done, or their results got lost or whether the doctors failed to record them.

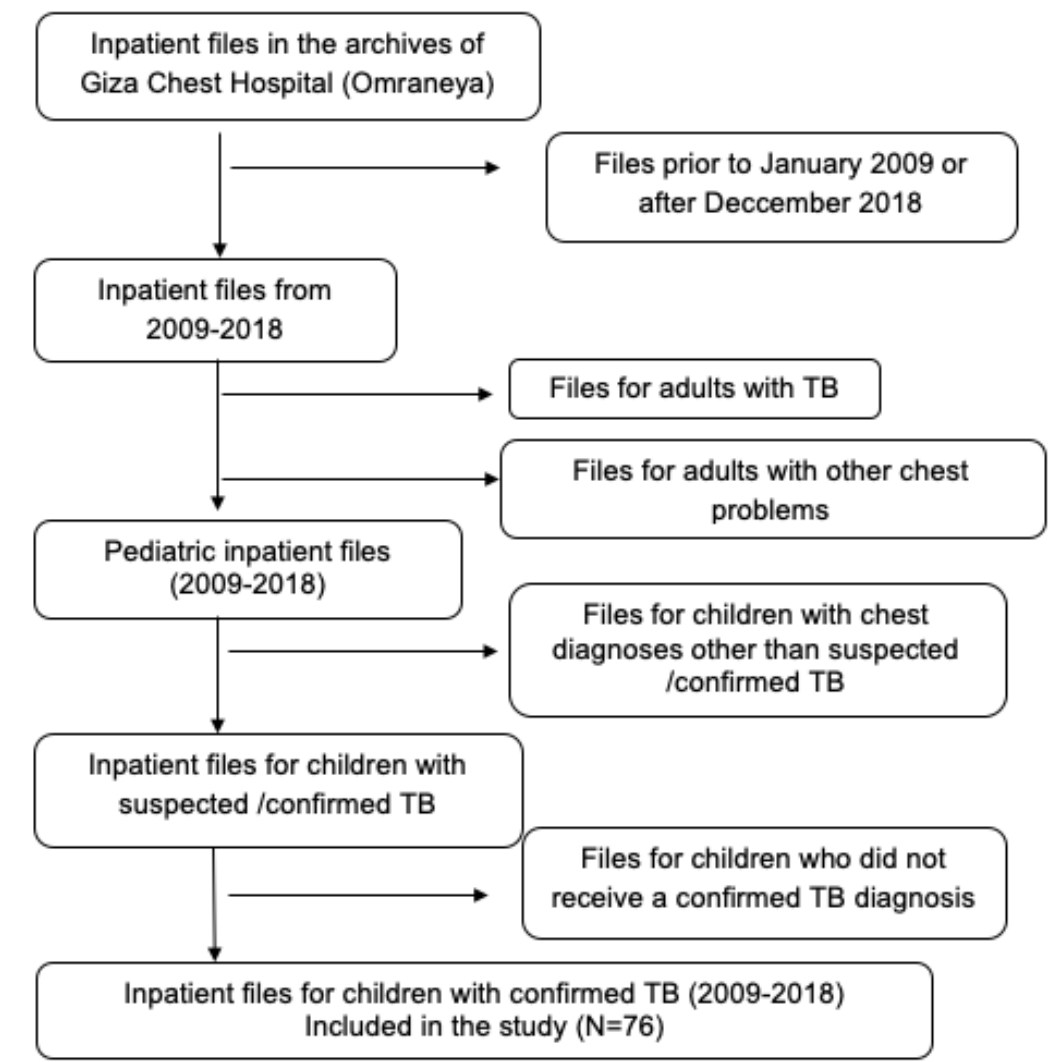

Figure (1): Flowchart for choice of included files in the study.

Table (1): Demographic data from the studied pediatric inpatient files.

\begin{tabular}{lcc}
\hline & Number & $\%$ \\
\hline Gender & & \\
\hline Male & 42 & 55.3 \\
\hline Female & 34 & 44.7 \\
\hline Total & 76 & 100 \\
\hline Age & & \\
\hline Pre-school (<6years) & 11 & 14.5 \\
\hline School (>6years) & 65 & 85.5 \\
\hline Total & 76 & 100 \\
\hline Residence & & \\
\hline Rural & 61 & 80.3 \\
\hline Urban & 15 & 19.7 \\
\hline Total & 76 & 100 \\
\hline
\end{tabular}

Only $53.9 \%$ of patients received DOTS therapy (table 2), and in table 4 it can be interpreted that DOTS implementation in children only started in 2011 in Giza Chest Hospital, hence the relatively low percentage. Table 3 shows that there was a statistically significant annual rate of decrease in the number of admitted pediatric cases (-2.714, $p$ value 0.001$)$ for the years 2009-2018, 
with no recorded pediatric inpatients in the last two years (see also figure 2). The decrease was noted across all age, sex and residential distributions (table 4).

Table (2): Clinical data from the studied pediatric inpatient files.

\begin{tabular}{|c|c|c|c|c|c|}
\hline & Number & $\%$ & & Number & $\%$ \\
\hline \multicolumn{3}{|c|}{ History of TB contact } & \multicolumn{3}{|c|}{ Result of Tuberculin test } \\
\hline Positive & 10 & 13.2 & Positive & 70 & 92.1 \\
\hline Negative & 66 & 86.8 & Negative & 6 & 7.9 \\
\hline Total & 76 & 100 & Total & 76 & 100 \\
\hline \multicolumn{3}{|c|}{ CXR Evidence of $T B$} & \multicolumn{3}{|c|}{ Results of sputum culture } \\
\hline Positive & 29 & 38.2 & Positive & 28 & 36.8 \\
\hline Negative & 3 & 3.9 & Negative & 3 & 3.9 \\
\hline $\mathrm{NA}$ & 44 & 57.9 & NA & 45 & 59.2 \\
\hline Total & 76 & 100 & Total & 76 & 100 \\
\hline \multicolumn{3}{|c|}{ Pathological Evidence of TB } & \multicolumn{3}{|c|}{ Site of TB } \\
\hline Positive & 46 & 60.5 & PTB & 31 & 40.8 \\
\hline Negative & 30 & 39.5 & $\mathrm{LN}$ & 20 & 26.2 \\
\hline Total & 76 & 100 & Pleura & 17 & 22.4 \\
\hline \multicolumn{3}{|c|}{ Treatment strategy } & Bone & 4 & 5.3 \\
\hline DOTS & 41 & 53.9 & $\mathrm{CNS}$ & 4 & 5.3 \\
\hline Other & 35 & 46.1 & Total & 76 & 100 \\
\hline Total & 76 & 100 & & & \\
\hline
\end{tabular}

CNS: central nervous system; CXR: chest $\mathrm{x}$ ray; DOTS: directly observed treatment short-course; LN: lymphadenopathy; NA: not available; PTB: pulmonary tuberculosis; TB: tuberculosis.

Table (3): Comparison between the yearly distribution of cases during 2009 to 2018 .

\begin{tabular}{lcccccc}
\hline \multirow{2}{*}{ Year } & \multicolumn{2}{c}{ Total TB patients } & \multicolumn{2}{c}{ PTB } & \multicolumn{2}{c}{ EPTB } \\
\cline { 2 - 7 } & Number & Percent & Number & Percent & Number & Percent \\
\hline $\mathbf{2 0 0 9}$ & 20 & 26.3 & 8 & 25.8 & 13 & 28.9 \\
\hline $\mathbf{2 0 1 0}$ & 15 & 19.7 & 5 & 16 & 10 & 22.2 \\
\hline $\mathbf{2 0 1 1}$ & 13 & 17.1 & 7 & 22.6 & 9 & 20 \\
\hline $\mathbf{2 0 1 2}$ & 14 & 18.4 & 7 & 22.6 & 5 & 11.1 \\
\hline $\mathbf{2 0 1 3}$ & 6 & 7.9 & 2 & 6.5 & 3 & 6.7 \\
\hline $\mathbf{2 0 1 4}$ & 5 & 6.6 & 2 & 6.5 & 2 & 4.4 \\
\hline $\mathbf{2 0 1 5}$ & 1 & 1.4 & - & - & 1 & 2.2 \\
\hline $\mathbf{2 0 1 6}$ & 2 & 2.6 & - & - & 2 & 4.4 \\
\hline $\mathbf{2 0 1 7}$ & - & - & - & - & - & - \\
\hline $\mathbf{2 0 1 8}$ & - & - & - & - & - & - \\
\hline Total & 76 & 100 & 31 & 100 & 45 & 100 \\
\hline $\begin{array}{l}\text { Annual rate } \\
\text { of change }\end{array}$ & -2.714 & & -1.202 & & -3.150 & \\
\hline $\boldsymbol{P}$ Value & $0.001^{* *}$ & \multicolumn{5}{c}{$0.002^{* *}$} \\
\hline
\end{tabular}

EPTB: Extra-pulmonary tuberculosis; PTB; pulmonary tuberculosis; TB: tuberculosis

\section{Discussion}

The demographic distribution detected in the studied files shows a slight male prevalence $(55.3 \% ; 1.2: 1)$ which is in accordance with the findings from most countries according to the latest WHO report and country profiles $(2-5)$.

However, there was a predominance of affection of school-aged children (85.5\%) in our study. Most literature states that pediatric TB is more common under five years of age followed by adolescence (18-20). This discrepancy prompts questioning if TB was under-suspected and underdiagnosed in the younger children in this chest center. Another possibility is that a confirmed diagnosis was more challenging in this younger age group. Moreover, patients from a 
rural background were a majority at $80.3 \%$, despite the center being urban based. Although many countries report a higher urban load $(21,22)$, our finding could be due to rural areas being underprivileged socioeconomically and in terms of sanitary and health services provided. Alternatively, urban reporting could be over-estimated in some countries, as they report cases by site of notification center rather than by patient residence (23).

Table (4): Yearly distribution of TB patients according to age, sex, residence and treatment received

\begin{tabular}{ccccccccc}
\hline \multirow{2}{*}{ Year } & \multicolumn{2}{c}{ Gender } & \multicolumn{2}{c}{ Age } & \multicolumn{2}{c}{ Residence } & \multicolumn{2}{c}{ Treatment } \\
\cline { 2 - 9 } & Male & Female & Preschool & School & Rural & Urban & Dots & Other \\
\hline $\mathbf{2 0 0 9}$ & 11 & 9 & 2 & 18 & 15 & 5 & 0 & 20 \\
\hline $\mathbf{2 0 1 0}$ & 7 & 8 & 4 & 11 & 11 & 4 & 0 & 15 \\
\hline $\mathbf{2 0 1 1}$ & 8 & 5 & 3 & 10 & 12 & 1 & 13 & 0 \\
\hline $\mathbf{2 0 1 2}$ & 8 & 6 & 2 & 12 & 11 & 3 & 14 & 0 \\
\hline $\mathbf{2 0 1 3}$ & 3 & 3 & 0 & 6 & 5 & 1 & 6 & 0 \\
\hline $\mathbf{2 0 1 4}$ & 3 & 2 & 0 & 5 & 4 & 1 & 5 & 0 \\
\hline $\mathbf{2 0 1 5}$ & 1 & 0 & 0 & 1 & 1 & 0 & 1 & 0 \\
\hline $\mathbf{2 0 1 6}$ & 1 & 1 & 0 & 2 & 2 & 0 & 2 & 0 \\
\hline $\mathbf{2 0 1 7}$ & 0 & 0 & 0 & 0 & 0 & 0 & 0 & 0 \\
\hline $\mathbf{2 0 1 8}$ & 0 & 0 & 0 & 0 & 0 & 0 & 0 & 0 \\
\hline Total & 42 & 34 & 11 & 65 & 61 & 15 & 41 & 35 \\
\hline DOTS: Directly Observed Treatment Short-course. & & & &
\end{tabular}

DOTS: Directly Observed Treatment Short-course.

Table 5: Correlation of Site of TB and other variables.

\begin{tabular}{|c|c|c|c|c|c|c|c|c|c|c|c|c|c|}
\hline \multirow{2}{*}{$\begin{array}{l}\text { Site } \\
\text { Age }\end{array}$} & \multicolumn{2}{|c|}{ РTB } & \multicolumn{2}{|c|}{ LN } & \multicolumn{2}{|c|}{ Pleura } & \multicolumn{2}{|c|}{ Bone } & \multicolumn{2}{|c|}{ CNS } & \multicolumn{2}{|c|}{ Total } & \multirow{2}{*}{$\begin{array}{c}P \\
\text { value }\end{array}$} \\
\hline & $\mathrm{N}$ & $\%$ & $\mathrm{~N}$ & $\%$ & $\mathrm{~N}$ & $\%$ & $\mathrm{~N}$ & $\%$ & $\mathrm{~N}$ & $\%$ & $\mathrm{~N}$ & $\%$ & \\
\hline Pre-school & 6 & 7.9 & 0 & 0 & 2 & 2.6 & 0 & 0 & 3 & 3.9 & 11 & 14.5 & \multirow[t]{3}{*}{0.002} \\
\hline School- age & 25 & 32.9 & 20 & 26.3 & 15 & 19.7 & 4 & 5.3 & 1 & 1.3 & 65 & 85.5 & \\
\hline Total & 31 & 40.8 & 20 & 26.3 & 17 & 22.4 & 4 & 5.3 & 4 & 5.3 & 76 & 100 & \\
\hline CXR findings & $\mathrm{N}$ & $\%$ & $\mathrm{~N}$ & $\%$ & $\mathrm{~N}$ & $\%$ & $\mathrm{~N}$ & $\%$ & $\mathrm{~N}$ & $\%$ & $\mathrm{~N}$ & $\%$ & \multirow{5}{*}{0.001} \\
\hline positive & 27 & 35.5 & - & - & 2 & 2.6 & - & - & - & - & 29 & 38.2 & \\
\hline negative & 3 & 3.9 & - & - & 0 & 0 & - & - & - & - & 3 & 3.9 & \\
\hline NA & 1 & 1.3 & 20 & 26.3 & 15 & 19.7 & 4 & 5.3 & 4 & 5.3 & 44 & 57.9 & \\
\hline Total & 31 & 93.8 & 20 & 26.3 & 17 & 22.4 & 4 & 5.3 & 4 & 5.3 & 76 & 100 & \\
\hline Sputum culture & $\mathrm{N}$ & $\%$ & $\mathrm{~N}$ & $\%$ & $\mathrm{~N}$ & $\%$ & $\mathrm{~N}$ & $\%$ & $\mathrm{~N}$ & $\%$ & $\mathrm{~N}$ & $\%$ & \multirow{5}{*}{0.001} \\
\hline positive & 26 & 34.2 & - & - & 2 & 6.5 & - & - & - & - & 28 & 36.8 & \\
\hline negative & 3 & 3.9 & - & - & - & - & - & - & - & - & 3 & 3.9 & \\
\hline NA & 2 & 2.6 & 20 & 26.3 & 15 & 19.7 & 4 & 5.3 & 4 & 5.3 & 45 & 59.2 & \\
\hline Total & 31 & 40.8 & 20 & 26.3 & 17 & 22.4 & 4 & 5.3 & 4 & 5.3 & 76 & 100 & \\
\hline Pathology & $\mathrm{N}$ & $\%$ & $\mathrm{~N}$ & $\%$ & $\mathrm{~N}$ & $\%$ & $\mathrm{~N}$ & $\%$ & $\mathrm{~N}$ & $\%$ & $\mathrm{~N}$ & $\%$ & \multirow{5}{*}{$* *$} \\
\hline positive & 3 & 3.9 & 20 & 26.3 & 15 & 19.7 & 4 & 5.3 & 4 & 5.3 & 46 & 60.5 & \\
\hline negative & - & - & - & - & - & - & - & - & - & - & - & - & \\
\hline NA & 28 & 36.8 & - & - & 2 & 2.6 & - & - & - & - & 30 & 39.5 & \\
\hline Total & 31 & 40.8 & 20 & 26.3 & 17 & 22.4 & 4 & 5.3 & 4 & 5.3 & 76 & 100 & \\
\hline
\end{tabular}

CNS: Central nervous system; LN: Lymph node: NA: Not available; PTB: Pulmonary tuberculosis; ${ }^{* *}$ : Chi x not possible as there are no negative results.

Regarding the clinical presentation, it was observed that extra-pulmonary TB (EPTB) was more (59.2\%) than PTB in this single-center in the ten years from 2009-2018. This is an interesting finding, especially when compared to an earlier Egyptian study by Samuel et al in 2000 (24) and most literature $(\mathbf{2}, \mathbf{1 8 - 2 1 , 2 5 )}$ where PTB had the upper hand. Although some studies show a percentage of EPTB as high as 46\% (26), PTB remained the most common 
presentation. A possible explanation is a difference in the study setting. Our studied files were for inpatients only, which are usually either newly diagnosed TB cases initiating treatment, or complicated cases.

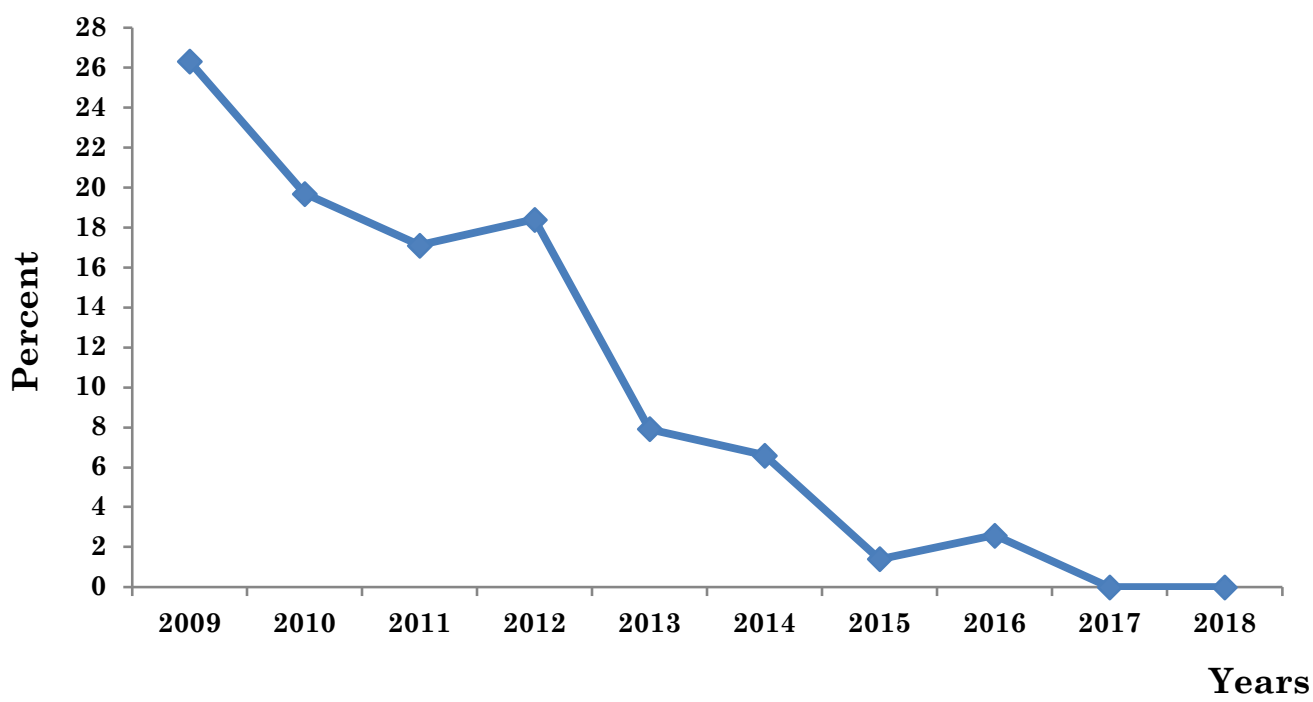

Figure (2): The yearly distribution of pediatric inpatients from January 2009 to December 2018.

Most stable cases of PTB, that are already established on treatment, follow up in the outpatient clinics. This difference in setting may have led to a bias towards EPTB numbers. However, this finding needs validation by further studies in more than one chest center, and in both outpatient and inpatient settings. We hope this finding stands true for the pediatric age group nationwide, this will open the door for a further in depth look for the cause of this change in pattern from the earlier study (24). Is malnourishment a culprit? Or has the adequate treatment of contact cases with open PTB led to a decrease in childhood PTB in favor of EPTB? There is room for more in depth research in that arena for pediatric TB in Egypt.

All sites affected by TB whether PTB or EPTB were more common in school-aged children except for tuberculous CNS affection that was more in preschool children. This finding is consistent with other studies where CNS TB was more common in early childhood, especially between 6 months and 5 years of age $(27,28)$. This is possibly due to this age being more vulnerable to malnutrition and viral infections, which renders preschool children more vulnerable for CNS TB (28).

Moreover, there was a significant annual rate of decrease in new pediatric cases in that center (-2.714, p value 0.001) for the years 2009-2018, with no recorded pediatric cases in the last two years. The decrease was noted across all age, sex and residence distributions, and was true for both pulmonary and extra-pulmonary TB. It is not clear, however, whether this reflects a true decrement in TB cases including those in need of hospitalization, or if this is a result of earlier diagnosis and more effective management strategies that led to less severe cases and thus less need for hospitalization. Promising as this is, the authors are aware that childhood tuberculosis remains under-diagnosed and under-reported in most countries due to difficulties in confirming diagnosis and lack of guidelines for systematic screening (29). Thus, a high index of suspicion and vigorous investigatory efforts are still required for prompt diagnosis of pediatric TB. This is essential to be able to report and initiate therapy in a timely and adequate manner, in a desire to augment these results aiming to achieve the WHO goals of halting and reversing the TB epidemic (12). Again our results are consistent with the fact that the overall incidence of TB is decreasing in Egypt (5) and globally despite lagging behind the ambitious WHO goals (8-11), but still await validation from other chest centers representing different regions in Egypt.

Forty-one patients (53.9\%) received the Directly Observed Therapy Short-course (DOTS). According to the Egyptian National Tuberculosis Control Program (6), DOTS treatment regimen was introduced in 1996 and reached nationwide implementation by 2001. This could be true for 
adult TB cases, however it was not registered in the pediatric files in Giza Chest Hospital (Omraneya) for the years 2009 and 2010. DOTS therapy was documented for all pediatric cases since 2011, and there has been a steady decrease in cases since, with no recorded pediatric TB inpatients in 2017 and 2018. Similar decreases were observed by other Egyptian researchers in other centers $(30,31)$. In contrast, when we compare the results from earlier studies like Sameul et al. in 2000 (24) before the nationwide implementation of DOTS, we find that the earlier study detected a steady increase in the total number of cases from 1986 to 1998 (with the exception of a transient decrease reported in 1994). Another possible explanation is the increase in the coverage rate of BCG vaccine in Egypt which reached a peak of 99\% in 2016 (32).

Furthermore, a positive Tuberculin test was found in 70 (90.1\%) of children with TB. However, a positive tuberculin test does not differentiate between latent TB infection and TB disease and thus high index of suspicion is needed to diagnose children with TB, along with more sensitive and specific testing (33). The lower results for sputum analysis and CXR are possibly due to the pauci-bacillary nature of PTB in children and non-specificity of radiologic findings respectively, in addition to being mainly geared to PTB. However, more recent tests like interferon Gamma Release Assay (IGRA) and molecular diagnostic studies like Xpert MTB/RIF assay and PCR for TB were not done or documented in the files, which summons a call for updating the laboratories of the Egyptian chest centers.

The authors are aware of the limitations to the study. The observation was from a single center, which is not indicative of all sectors of the community, and awaits validation from other chest centers. The filing system was hand-written paper files stored in an archive room, rather than a computerized system. This system is amenable to loss, fading, destruction, in addition not all data were filled in for all patients. Data regarding socio-economic standard, pollution, and risk factors (other than TB exposure) were not documented in the files. Thus, we strongly recommend upgrading the available diagnostic modalities, and the system for registering, filing and archiving of data to a computer-based one. Moreover, a continuation of the nationwide compulsory BCG vaccination program, as well DOTS therapy for the diagnosed TB cases is encouraged. Research on a larger scale is also important to validate the observed patterns.

\section{Conclusion}

Extra-pulmonary tuberculosis was the more common presentation among children hospitalized for tuberculosis, over a decade in the studied chest center. Lymph node affection came second to pulmonary TB, followed by pleural affection, while bones and CNS were the least affected sites. The studied cohort had a majority of rural and school-aged children. Raising awareness among the physicians regarding the spectrum of clinical presentations of pediatric TB, especially raising the suspicion index for TB in the preschool age, is highly recommended.

\section{Acknowledgement}

The authors would like to acknowledge the heads, managers and workers in Giza Chest Hospital (Omraneya), Egypt for granting permission to access the pediatric inpatient files and making this work possible. The authors would also like to acknowledge the efforts of late Prof. Dr. Samiha Samuel, Prof. Dr. Sonia Al-Saiedi and Prof. Dr. Tarek Imam for their contributions in the study [15] used for comparison. Thanks are also due to Prof. Dr. Amani Moussa for helping with the statistical analysis.

\section{Author Contributions:}

All authors shared in the data collection, literature review, analysis of results and drafting of the work. C.W.S.B. submitted the manuscript and corresponded until publication. All authors have read and agreed to the published version of the manuscript.

\section{FUNDING}

Authors declare there was no extramural funding provided for this study. 


\section{CONFLICT OF INTEREST}

The authors declare no conflict of interest in connection with the reported study. Authors declare veracity of information.

\section{References}

1. S. Tenny, M. Varacallo, Evidence Based Medicine. (StatPearls Publishing; Treasure Island (FL), 2020; https://www.ncbi.nlm.nih.gov/books/NBK470182/).

2. World Health Organization, Global tuberculosis report 2020 (2020), (available at https://www.who.int/publications/i/item/9789240013131).

3. R. S. Wallis, M. Pai, D. Menzies, T. M. Doherty, G. Walzl, M. D. Perkins, A. Zumla, Biomarkers and diagnostics for tuberculosis: progress, needs, and translation into practice. Lancet Lond. Engl. 375, 1920-1937 (2010).

4. D. Gómez Pastrana Durán, R. Torronteras Santiago, P. Caro Mateo, A. M. López Barrio, P. Macías Mardones, A. Andrés Martín, M. Pineda Mantecon, J. Navarro González, [Effectiveness of smears and cultures in gastric aspirate samples in the diagnosis of tuberculosis]. An. Esp. Pediatr. 53, 405-411 (2000).

5. World Health Organization, Tuberculosis profile: Egypt (2019), (available at http://www.who.int/tb/data/).

6. Ministry of Health, National Tuberculosis Control Program (NTP) Egypt (2015), (available at http://ccs.gov.eg/ntp/NTP_introd.htm.).

7. M. F. Negm, G. F. Al mehy, T. M. Ali, S. S. Abd Elfadil, Tuberculosis situation in Ismailia governorate (2002-2012) before and after Direct Observed Therapy Short Course Strategy (DOTS). Egypt. J. Chest Dis. Tuberc. 65, 211-217 (2016).

8. Public Health England press office, Tuberculosis rates in England hit lowest recorded levels (2018), (available at https://www.gov.uk/government/news/tuberculosis-rates-in-englandhit-lowest-recorded-levels).

9. Division of Tuberculosis Elimination, Trends in Tuberculosis, 2019 (2020), (available at https://www.cdc.gov/tb/publications/factsheets/statistics/tbtrends.htm).

10. R. Prasad, N. Gupta, A. Banka, 2025 too short time to eliminate tuberculosis from India. Lung India Off. Organ Indian Chest Soc. 34, 409-410 (2017).

11. S. Zhu, L. Xia, S. Yu, S. Chen, J. Zhang, The burden and challenges of tuberculosis in China: findings from the Global Burden of Disease Study 2015. Sci. Rep. 7, 14601 (2017).

12. Geneva: World Health Organization, End TB Strategy: global strategy and targets for tuberculosis prevention, care and control after 2015. (2014), (available at https://www.who.int/tb/strategy/End_TB_Strategy.pdf?ua=1).

13. K. J. Seung, S. Keshavjee, M. L. Rich, Multidrug-Resistant Tuberculosis and Extensively Drug-Resistant Tuberculosis. Cold Spring Harb. Perspect. Med. 5, a017863 (2015).

14. A. L. Vecchio, M. Bocchino, L. Lancella, C. Gabiano, S. Garazzino, R. Scotto, I. Raffaldi, L. R. Assante, A. Villani, S. Esposito, A. Guarino, Indications to Hospital Admission and Isolation of Children With Possible or Defined Tuberculosis: Systematic Review and Proposed Recommendations for Pediatric Patients Living in Developed Countries. [Corrected]. Medicine (Baltimore). 94, e2045 (2015).

15. World Health Organization, A people-centred model of tuberculosis care: A blueprint for eastern European and central Asian countries, first edition (2017), (available at http://www.euro.who.int/ pubrequest).

16. Central agency for Public Mobilization and Statistics, The Egyptian Census - Population. (2017; https://www.capmas.gov.eg/Pages/Publications.aspx?page_id=5109\&Year=23354).

17. World Medical Association, WMA Declaration of Helsinki- Ethical Principles for Medical Research Involving Human Subjects (2013), (available at https://www.wma.net/policiespost/wma-declaration-of-helsinki-ethical-principles-for-medical-research-involvinghuman-subjects/2013/).

18. Division of Tuberculosis Elimination, TB in Children (2020), (available at https://www.cdc.gov/tb/topic/populations/tbinchildren/default.htm).

19. T. A. Thomas, Tuberculosis in Children. Pediatr. Clin. North Am. 64, 893-909 (2017).

20. J. Brandão Silva, J. Caldeira Santos, L. Barbosa, I. Carvalho, [Tuberculosis in the paediatric age group: A reflection on transmission]. An. Pediatr. Barc. Spain 2003. 94, 403411 (2021). 
21. World Health Organization, Stop TB Partnership Executive Director's Report November 2020 (Digital)

(2020; http://www.stoptb.org/assets/documents/resources/publications/acsm/kp_rural_spreads.pd f.).

22. I. Shah, D. Tolani, N. Bansal, Geographical and demographic profile of tuberculosis in a pediatric population in Mumbai - A retrospective cross-sectional hospital-based study. Clin. Epidemiol. Glob. Health. 4, 193-196 (2016).

23. D. Datiko, A. Hadgu, D. Jerene, P. G. Suarez, High urban tuberculosis case notification rates can be misleading: evidence from an urban setting in Ethiopia. BMC Public Health. 20, 302 (2020).

24. Sameul S, El- Saiedi S, Imam I, The pattern of tuberculosis in Egyptian children: 12 years experience. 48 (2000).

25. C. T. Sreeramareddy, N. Ramakrishnareddy, R. K. Shah, R. Baniya, P. K. Swain, Clinicoepidemiological profile and diagnostic procedures of pediatric tuberculosis in a tertiary care hospital of western Nepal-a case-series analysis. BMC Pediatr. 10, 57 (2010).

26. S. K. Jain, A. Ordonez, A. Kinikar, N. Gupte, M. Thakar, V. Mave, J. Jubulis, S. Dharmshale, S. Desai, S. Hatolkar, A. Kagal, A. Lalvani, A. Gupta, R. Bharadwaj, Pediatric Tuberculosis in Young Children in India: A Prospective Study. BioMed Res. Int. 2013, 1-7 (2013).

27. K. Bourgi, C. Fiske, T. R. Sterling, Tuberculosis Meningitis. Curr. Infect. Dis. Rep. 19, 39 (2017).

28. A. Yaramiş, F. Gurkan, M. Elevli, M. Söker, K. Haspolat, G. Kirbaş, M. A. Taş, Central nervous system tuberculosis in children: a review of 214 cases. Pediatrics. 102, E49 (1998).

29. M. R. Karim, M. A. Rahman, S. A. Mamun, M. A. Alam, S. Akhter, Risk factors of childhood tuberculosis: a case control study from rural Bangladesh. WHO South-East Asia J. Public Health. 1, 76-84 (2012).

30. E. Sobh, S. A. E. Kinawy, Y. M. A. Abdelkarim, M. A. Arafa, The pattern of tuberculosis in Aswan Chest Hospital, Egypt. Int. J. Mycobacteriology. 5, 333-340 (2016).

31. A. Saad-Hussein, A. M. Mohammed, Trend of application of World Health Organization control strategy of tuberculosis in Egypt. J. Epidemiol. Glob. Health. 4, 195 (2014).

32. WHO and UNICEF estimates of national immunization coverage, Egypt: WHO and UNICEF estimates of immunization coverage: 2014 revision (2015), (available at http://www.data.unicef.org/child-health/immunization).

33. Division of Tuberculosis Elimination, Testing for TB Infection (2021), (available at https://www.cdc.gov/tb/topic/testing/tbtesttypes.htm).

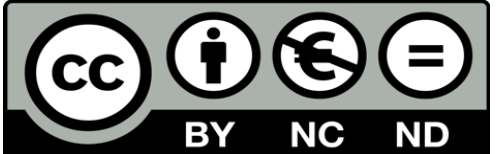

(C) 2021 submitted by the authors. Open access publication under the terms and conditions of the Creative Commons Attribution (CC- BYNC- ND) license. (https://creativecommons.org/licenses/by-nc-nd/2.0/). 